\author{
Marcelo E. Bigal \\ Richard B. Lipton
}

\author{
M.E. Bigal (凶) \\ Department of Neurology, \\ Albert Einstein College of Medicine, \\ 1300 Morris Park Avenue, \\ Bronx, NY, 10461, USA \\ e-mail: mbigal@aecom.yu.edu \\ Tel.: +1-718-4303844 \\ M.E. Bigal \\ The New England Center for Headache, \\ Stamford, CT, USA
}

\section{R.B. Lipton}

Department of Neurology,

Epidemiology and Population Health,

Albert Einstein College of Medicine,

Bronx, NY, USA

\section{Overview on the prevalence and impact of migraine}

\begin{abstract}
Migraine is a highly prevalent headache disorder that has a substantial impact on the individual and society. Over the past decade, substantial advances in research have increased understanding of the pathophysiology, diagnosis, epidemiology, and treatment of the disorder. This article reviews the burden of migraine, emphasizing the population-based studies that used standardized diagnostic criteria.
\end{abstract}

Key words Migraine • Epidemiology $\cdot$ Impact

\section{Introduction}

Headache disorders include a number of conditions characterized by recurrent episodes of head pain and associated symptoms. Though almost everyone gets occasional headaches, particular headache disorders vary in incidence, prevalence, and duration. Headache disorders are divided into the primary and secondary disorders. Secondary disorders have an identifiable underlying cause, such as an infection, a brain tumor, or stroke. In primary headache disorders, there is no apparent underlying cause $[1,2]$.
Migraine is one of the most burdensome of the primary headache disorders [3-5]. The first population studies to apply the International Headache Society (IHS) criteria were conducted in Copenhagen; the population distribution of all headache disorders was examined using in-person clinical assessment in a large, representative community sample $[4,5]$. The lifetime prevalences of various headache disorders from this population are summarized in Table 1.

Tension-type headache is a far more common primary headache than migraine $[4,5]$. Cluster headache is relatively uncommon, with a prevalence of $0.1 \%$ of this population $[4,5]$. Of the secondary headaches, fasting 
Table 1 Lifetime prevalence of primary and secondary headaches (after $[4,5]$ )

\begin{tabular}{lr}
\hline Type & Prevalence $(\%)$ \\
\hline Primary & \\
$\quad$ Tension-type headache & 78 \\
$\quad$ Migraine & 16 \\
Secondary & \\
$\quad$ Fasting & 19 \\
Nose/sinus disease & 15 \\
Head trauma & 4 \\
$\quad$ Nonvascular intracranial disease & 0.5 \\
(brain tumor and other disorders) & \\
\hline
\end{tabular}

headache (a headache precipitated by missing meals) is the most common type, followed by the headache due to nose/sinus disease and headache secondary to head trauma. Nonvascular intracranial diseases, which include infections and brain tumors, were rare. For the rest of this review, we focus on migraine.

\section{Migraine incidence and prevalence}

Stewart et al. estimated migraine incidence using reported age of onset from a prevalence study [6, 7]. In males, the incidence of migraine with aura peaked around 5 years of age at 6.6/1,000 person-years; the peak for migraine without aura was 10/1,000 person-years between 10 and 11 years of age. New cases of migraine were uncommon in men in their twenties. In females, the incidence of migraine with aura peaked between ages 12 and $13(14.1 / 1,000$ person-years); migraine without aura peaked between ages 14 and 17 (18.9/1,000 person-years). Thus, migraine begins earlier in males than in females and migraine with aura begins earlier than does migraine without aura.

The published estimates of migraine prevalence have varied widely. In the greater Copenhagen study, for men, the lifetime prevalences were $93 \%$ for any kind of headache, $8 \%$ for migraine, and $69 \%$ for tension-type headache [5]. For women, the lifetime prevalences were $99 \%$ for all headache, $25 \%$ for migraine, and $88 \%$ for tension-type headache. The 1-year prevalence of migraine was $6 \%$ in men and $16 \%$ in women; the 1-year prevalence of tension-type headache was $63 \%$ and $86 \%$ respectively.

In the United States, the first American Migraine Study, based on data collected in 1989, used questionnaires mailed to 15,000 households selected to be representative of the US population [7]. Migraine diagnoses were based on the IHS criteria but headache duration and the lifetime number of previous migraine attacks were not considered. A follow-up study, the American Migraine Study II, used virtually identical methodology 10 years later and demonstrated very similar prevalence estimates [8].

A meta-analytic summary of the prevalence studies show that prevalence increases throughout childhood and early adult life until approximately age 40, after which it declines (Fig. 1) [3].

The female-to-male migraine prevalence ratio also varies with age [3]. The onset of hormonal changes associated with menses may contribute to this variation. However, hormonal factors cannot be the sole cause; differences persist up to age 70 years and beyond, well

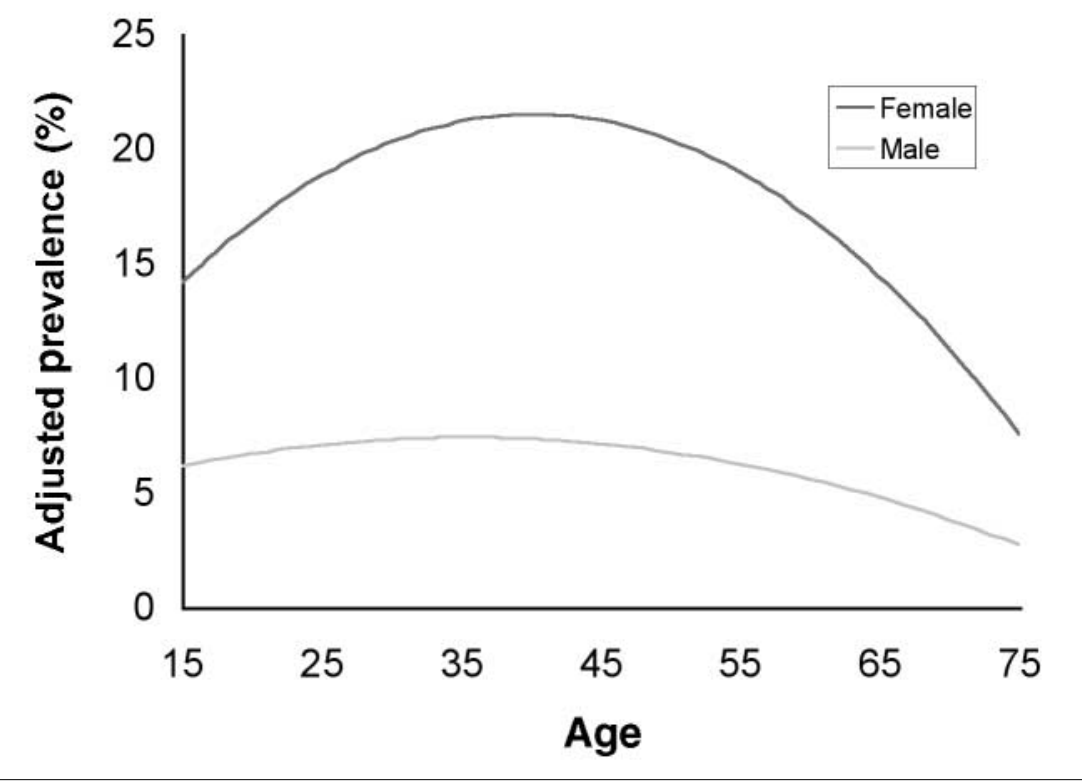

Fig. 1 Adjusted prevalence of migraine by age from a meta-analysis of studies using IHS criteria. (From [3], modified) 
Fig. 2 Adjusted prevalence of migraine by geographic area and gender in a metaanalysis of studies using IHS criteria. (From [3], modified)

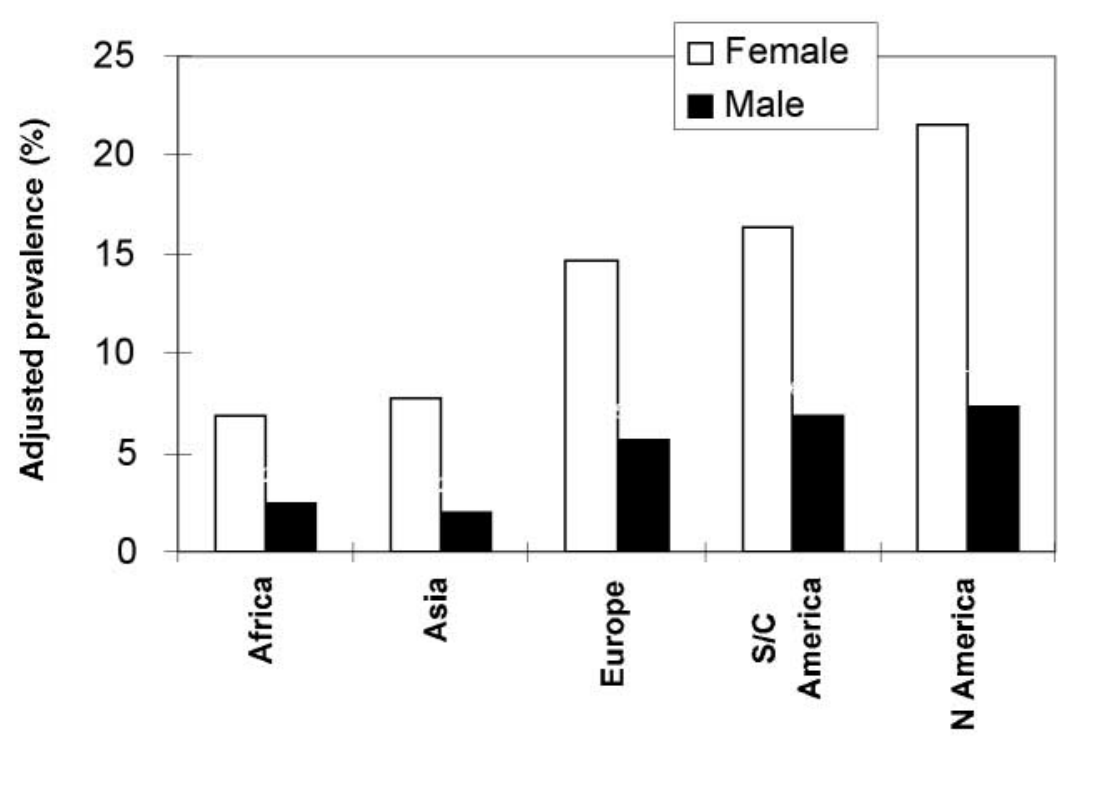

beyond the time that cyclical hormonal changes can be considered a factor [10].

Population studies show that individuals from highincome groups were much more likely to report a medical diagnosis of migraine than were those with lower income [11]. Perhaps migraine appears to be a disease of persons with high income in the doctor's office because high income individuals seek care.

Migraine prevalence also varies by race and geography. In the United States, it is highest in Caucasians, intermediate in African Americans, and lowest in Asian Americans [3]. Similarly, a meta-analysis of prevalence studies suggest that migraine is most common in North and South America, similar in Europe, but lower in Africa, and often lowest in studies from Asia (Fig. 2) [3]. The influence of reporting bias on these findings cannot be excluded. Nonetheless, the data suggest that race-related differences in genetic risk may contribute.

\section{Individual burden of migraine}

Migraine is a public health problem of enormous scope that has an impact on both the individual sufferer and on society [4-8]. The American Migraine Study II estimates that 28 million U.S. residents have severe migraine headaches [8]. Nearly one in four U.S. households has someone with migraine. Twenty-five percent of women in the United States who have migraine experience four or more severe attacks a month; $35 \%$ experience one to four severe attacks a month; $38 \%$ experience one, or less than one, severe attack a month [8]. Similar frequency patterns were observed for men [8].

In the American Migraine Study II, $92 \%$ of women and $89 \%$ of men with severe migraine had some headache-related disability [8]. About half were severely disabled or needed bed rest [12]. In addition to the attack-related disability, many migraineurs live in fear, knowing that at any time an attack could disrupt their ability to work, care for their families, or meet social obligations. Abundant evidence indicates that migraine reduces health-related quality of life.

\section{Societal impact of migraine}

Migraine has an enormous impact on society. Recent U.S. studies have evaluated both the indirect costs of migraine as well as the direct costs [13-15]. Indirect costs include the aggregate effects of migraine on productivity at work (paid employment), in household work, and in other roles. The largest component of indirect costs is the productivity losses that take the form of absenteeism and reduced productivity while at work. Hu et al. estimated that productivity losses due to migraine cost American employers U.S. $\$ 13$ billion per year [13-15]. These issues have been recently reviewed in more detail elsewhere [13-16].

The impact of migraine on healthcare utilization is marked as well. The National Ambulatory Medical Care Survey, conducted from 1976 to 1977 , found that $4 \%$ of all 
visits to physicians' offices (over 10 million visits a year) were for headache [17]. Migraine also results in major utilization of emergency rooms and urgent care centers. Vast amounts of prescription and over-the-counter (OTC) medications are taken for headache disorders. OTC sales of pain medication (for all conditions) were estimated to be U.S.\$ 3.2 billion in 1999 and headache accounts for about one-third of OTC analgesic use (Consumer Healthcare Products Association; OTC Sales Statistics 1995-1999; A.C. Neilsen, April 2000). Gross sales for the triptans are about U.S.\$ 1 billion per year in the United States.

Migraine is a lifelong disorder. Bille followed up a cohort of children with severe migraine for up to 37 years $[18,20]$. As young adults, $62 \%$ were migraine-free for more than 2 years, but only $40 \%$ continued to be migraine-free after 30 years, suggesting that migraine is often a lifelong disorder.

\section{Conclusions}

Using the IHS criteria, large population-based epidemiological studies from most regions of the world have shed light on the descriptive epidemiology and burden of headache. While migraine is a remarkably common cause of temporary disability, many migraineurs, even those with disabling headache, have never consulted a physician for the problem. Prevalence is highest in women, in persons between the ages of 25 and 55 years, and, at least in the United States, in individuals from low-income households. Nonetheless, prevalence is high in groups other than these high-risk groups. Migraine prevalence may be increasing in the United States, but this has not been proven. Longitudinal studies are required to better determine the incidence and natural history of migraine as well as the life course of comorbid conditions.

\section{References}

1. Raskin NH (1998) Headache, 2nd edn. Churchill-Livingstone, New York

2. Waters WE (1986) Headache (Series in Clinical Epidemiology). PSG, Littleton, MA

3. Scher AI, Stewart WF, Lipton RB (1999) Migraine and headache: a metaanalytic approach. In: Crombie IK (ed) Epidemiology of pain. IASP Press, Seattle, pp 159-170

4. Rasmussen BK (1995) Epidemiology of headache. Cephalalgia 15:45-68

5. Rasmussen BK, Jensen R, Schroll M, Olesen J (1991) Epidemiology of headache in a general population - a prevalence study. J Clin Epidemiol 44:1147-57

6. Stewart WF, Lipton RB, Celentano DD, Reed ML (1992) Prevalence of migraine headache in the United States. JAMA 267:64-69

7. Stewart WF, Linet MS, Celentano DD, Van Natta M, Ziegler D (1993) Age and sex-specific incidence rates of migraine with and without visual aura. Am J Epidemiol 34:1111-1120

8. Lipton RB, Stewart WF, Diamond S, Diamond ML, Reed M (2001)

Prevalence and burden of migraine in the United States: data from the American Migraine Study II. Headache 41:646-657
9. Lipton RB, Stewart WF, Diamond S, Diamond ML, Reed M (2001) Prevalence and Burden of migraine in the United States: data from the American Migraine Study II. Headache 41:646-657

10. Silberstein SD, Merriam GR (1997) Sex hormones and headache. In: Goadsby P, Silberstein SD (eds) Blue books of practical neurology: headache. Butterworth Heinemann, Boston, pp 143-176

11. Lipton RB, Stewart WF, Celentano DD, Reed ML (1992) Undiagnosed migraine: a comparison of symptombased and self-reported physician diagnosis. Arch Int Med 152:1273-1278

12. Stang PE, Yanagihara T, Swanson JW et al (1992) Incidence of migraine headaches: a population-based study in Olmstead County, Minnesota.

Neurology 42:1657-1662

13. Hu XH, Markson LE, Lipton RB, Stewart WF, Berger ML (1999) Burden of migraine in the United States: disability and economic costs. Arch Intern Med 159:813-818

14. Osterhaus JT, Gutterman DL, Plachetka JR (1992) Health care resources and lost labor costs of migraine headaches in the United States. Pharmacoeconomics 2:67-76
15. Holmes WF, MacGregor A, Dodick D (2001) Migraine-related disability: impact and implications for sufferers' lives and clinical issues. Neurology 56 [Suppl 1]:S13-S19

16. National Center for Health Statistics (1979) Vital and Health Statistics of the United States. DHEW, PHS publication no. 53. Advance data. National Center for Health Statistics, Hyattsville

17. Celentano DD, Stewart WF, Lipton RB, Reed ML (1992) Medication use and disability among migraineurs: a national probability sample. Headache 32:223-228

18. Bille B (1962) Migraine in school children. Acta Paediatr Scand 51[Suppl 136]:1-151

19. Bille B (1989) Migraine in children: prevalence, clinical features, and a 30year follow-up. In: Ferrari MD and Lataste X (eds) Migraine and other headaches. Parthenon, New Jersey

20. Stewart WF, Lipton RB, Simon D (1996) Work-related disability: results from the American Migraine study. Cephalalgia 16:231-238 